BAREKENG: Jurnal Ilmu Matematika dan Terapan

March $2021 \quad$ Vol. 15 No. 1 Page 009-014

P-ISSN: 1978-7227 E-ISSN: 2615-3017

doi : https://doi.org/10.30598/barekengvol15iss1pp009-014

\title{
APLIKASI MODEL RANTAI MARKOV UNTUK MENGANALISIS TINGKAT KENYAMANAN DI KOTA MAJENE BERDASARKAN TEMPERATURE HUMIDITY INDEX (THI)
}

\section{The Application of Markov Chain Model to Analyze the Comfortable Level in Majene City based on the Temperature Humidity Index (THI)}

\author{
Muhammad Abdy $^{1 *}$, Wahidah Sanusi ${ }^{2}$, Rahmawati $^{3}$ \\ ${ }^{1,2}$ Jurusan Matematika, FMIPA, Universitas Negeri Makassar \\ Jl. Daeng Tata - Kampus Parangtambung, Makassar, Indonesia \\ ${ }^{3}$ Jurusan Matematika, FMIPA, Universitas Sulawesi Barat \\ Jln. Prof. Baharuddin Lopa, SH., Majene, Sulbar, Indonesia \\ Corresponding author e-mail: $1 *$ muh.abdy@unm.ac.id
}

\begin{abstract}
Abstrak
Penelitian ini mengaplikasikan model rantai Markov pada data temperatur dan kelembaban relatif harian yang dikumpulan oleh stasiun Badan Meteoreologi dan Geofisika kabupaten Majene dari tahun 1983 sampai dengan tahun 2011. Penelitian ini bertujuan untuk menganalisis kategori tingkat kenyamanan di Kota Majene berdasarkan nilai Temperature Humidity Index dengan menghitung nilai peluang keadaan-tunaknya, nilai harapan masa tinggal dan nilai harapan masa perulangan pertama. Pengkategorian tingkat kenyamanan yang didasarkan kepada nilai Temperature Humidity Index, terdiri dari tiga kategori, yaitu kategori nyaman, cukup nyaman dan tidak nyaman. Trend tingkat kenyamanan di Kota Majene sepanjang tahun 1983 sampai tahun 2011 berfluktuasi di kategori cukup nyaman dan tidak nyaman. Kategori tidak nyaman terjadi di bulan Oktober dan November setiap tahunnya. Nilai peluang keadaan-tunak menunjukkan bahwa kategori cukup nyaman mempunyai peluang kemunculan yang terbesar, yaitu sekitar 70\%, dan kategori nyaman mempunyai peluang kemunculan yang paling kecil, yaitu hanya sekitar 5\%. Sementara dari nilai harapan masa tinggal dan nilai harapan masa perulangan pertama menunjukkan bahwa kategori cukup nyaman mempunyai durasi kemunculan terlama, yaitu sekitar 5 hari, dan mempunyai durasi paling singkat untuk muncul kembali setelah kemunculan sebelumnya, yaitu sekitar 1,43 hari.
\end{abstract}

Kata Kunci : rantai Markov, tingkat kenyamanan, Temperature Humidity Index-

Abstract

This study applied the Markov chain model on the daily temperature and relative humidity data that was collected from the Meteorology and Geophysics Agency station in Majene district for the period 1983 to 2011. This study aims to analyze the comfortable level category in the Majene city based on the Temperature Humidity Index by calculating the probability of steady-state, the mean residence time and the mean first passage time. Categorizing the level of comfortable which is based on the Temperature Humidity Index consists of three categories, namely the comfortable, quite comfortable and uncomfortable. The trend of comfortable levels in the Majene city from 1983 to 2011 was fluctuated in the categories of quite comfortable and uncomfortable. Uncomfortable category occurs in October and November each year. The steady-state probability values indicates that the quite comfortable category has the highest chance of appearance, which is around $70 \%$, and the comfortable category has the smallest chance of appearance, which is only about $5 \%$. Meanwhile the mean residence time and the mean first passage time indicate that the quite comfortable category have the longest duration of occurrence, which is around 5 days, and has the shortest duration to recur after occurring in the previous event, which is around 1.43 days.

Keywords: Markov chain, comfortable level, Temperature Humidity Index.

Article info:

Submitted: $01^{\text {st }}$ June 2020

Accepted: $19^{\text {th }}$ February 2021

How to cite this article:

M. Abdy, W. Sanusi, Rahmawati, “APLIKASI MODEL RANTAI MARKOV UNTUK MENGANALISIS TINGKAT KENYAMANAN DI KOTA MAJENE BERDASARKAN TEMPERATURE HUMIDITY INDEX (THI)”, BAREKENG: J. Il. Mat. \& Ter., vol. 15, no. 1, pp. 009014, Mar. 2021.

This work is licensed under a Creative Commons Attribution-ShareAlike 4.0 International License.

Copyright (C) 2021 Muhammad Abdy, Wahida Sanusi, and Rahmawati 


\section{PENDAHULUAN}

Pemodelan dan prediksi merupakan hal yang sangat penting dalam menyelidiki pola kondisi atmosfir. Berbagai metode telah dikembangkan untuk memperoleh model yang dapat digunakan untuk meramalkan cuaca. Akan tetapi karena sifat dan kondisi yang tidak konstan dari atmosfir, maka sulit dikembangkan dengan hanya menggunakan matematika yang deterministik [1]. Untuk memodelkan perubahan iklim yang tidak bersifat deterministik tersebut, maka proses stokastik merupakan salah satu metode pendekatan yang dapat digunakan. Pendekatan stokastik digunakan oleh [2], [3], [4], [5], [6] untuk memodelkan perubahan iklim. Demikian juga, [7] mengunakan model rantai Markov hidden untuk memodelkan masalah keuangan, perubahan iklim dan analisis gempa bumi.

Perubahan suhu udara sebagai salah satu unsur iklim yang semakin meningkat sangat dirasakan dan berpengaruh langsung terhadap tingkat kenyamanan manusia. Selain suhu udara, kenyamanan juga dipengaruhi oleh kelembaban relatif dan subjek yang merasakan kenyamanan [8]. Sebagai salah satu unsur iklim, suhu udara dan kelembaban relative merupakan suatu variable yang bersifat stokastik. Sifat stokastik ini menyebabkan suhu udara dan kelembaban relative dapat dianalisis dengan menggunakan model rantai Markov. Berbagai paper tentang tingkat kenyamanan telah ditulis, diantaranya dalam [1] yang memodelkan kenyamanan termal di wilayah utara semenanjung Malaysia berdasarkan Physiological Equivalent Temperature (PET). Kemudian, [9] menganalisis suhu yang nyaman di Negara Jerman dan USA. American National Standard Institute [10] mendefinisikan kenyamanan termal sebagai kondisi pikiran yang mengekspresikan kepuasan dalam lingkungan termal yang dinilai secara subjektif.

Secara kuantitatif, tingkat kenyamanan termal dapat dinyatakan dengan suatu indeks, diantaranya adalah Temperature Humidity Index (THI), yang pertama kali diperkenalkan oleh Thom tahun 1959 [11], kemudian dimodifikasi oleh Nieuwolt (1977) untuk daerah tropis [12]. Indeks kenyamanan lain yang telah digunakan diantaranya: Discomfort Index, Effective Temperature, Predicted Mean Vote, Wet Bulb Globe Temperature, Relative Strain Index, Physiological Equivalent Temperature dan lain-lain [8]. Batas kenyamanan rumus-rumus indeks tersebut mempunyai skala dan batas yang berbeda-beda.

Kondisi geografis Kota Majene yang sebagian berada dipesisir pantai dan sebagian lagi berada diperbukitan mempunyai kondisi suhu dan kelembaban relatif yang berubah-ubah. Kondisi tersebut sangat mempengaruhi tingkat kenyamanan yang dirasakan oleh masyarakat yang bermukim di Kota Majene dan sekitarnya.

Tujuan dari penelitian ini adalah menganalisis karakteristik tingkat kenyamanan termal berdasarkan indeks THI dengan menggunakan model rantai Markov. Karakteristik tingkat kenyamanan termal yang dianalisis adalah (a) peluang keadaan-tunak tingkat kenyamanan, (b) nilai harapan durasi terjadinya suatu tingkat kenyamanan, dan (c) nilai harapan durasi terjadinya kembali suatu tingkat kenyamanan setelah kejadian sebelumnya.

\section{METODE PENELITIAN}

Penelitian ini menggunakan prinsip rantai Markov dan beberapa sifat-sifatnya. Beberapa konsep dan sifatnya diberikan sebagai berikut:

\subsection{Rantai Markov}

Suatu proses stokastik $X=\left\{X_{t}, t=0,1,2, \ldots\right\}$ merupakan rantai Markov jika nilai proses pada waktu $t+1$, yaitu $X_{t+1}$, hanya bergantung pada nilai pada waktu $t$ atau $X_{t}$, yaitu:

" $t$ dan untuk semua keadaan $i_{0}, i_{1}, \ldots, i_{t+1}$, maka:

$\operatorname{Pr}\left(X_{t+1}=i_{t+1} \mid X_{t}=i_{t}, \ldots, X_{0}=i_{0}\right)=\operatorname{Pr}\left(X_{t+1}=i_{t+1} \mid X_{t}=i_{t}\right)$

Rantai Markov $\left\{X_{t}\right\}$ disebut homogen jika untuk semua keadaan $i$ dan $j$, maka

$\operatorname{Pr}\left(X_{t+k+1}=j \mid X_{t+k}=i\right)=\operatorname{Pr}\left(X_{t+1}=j \mid X_{t}=i\right), k=0,1,2, \ldots$

Misalkan $\operatorname{Pr}\left(X_{t+1}=j \mid X_{t}=i\right)=p_{i j}$ merupakan peluang transisi dari keadaan $i$ pada waktu $t$ ke keadaan $j$ pada waktu $t+1$, maka $p_{i j}$ dapat dinyatakan dalam bentuk matriks peluang transisi $P$, sebagai berikut: 


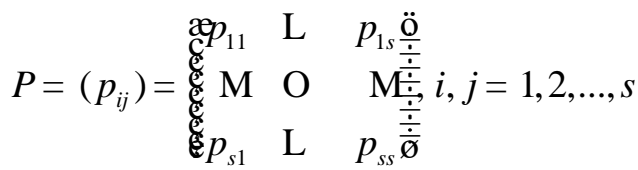

Dimana $0 £ p_{i j} £ 0$ dan $\underset{j \mathrm{I} S}{\AA} p_{i j}=1, i=1,2, \ldots, s ;$ dan $s$ adalah banyaknya keadaan.

Nilai-nilai $p_{i j}$ dapat diduga dari data yang diberikan. Salah satu metode penduga yang sederhana dan sering digunakan adalah metode kemungkinan maksimum [13], yaitu:

$$
\hat{p}_{i j}=\frac{f_{i j}}{F_{i}}
$$

dimana $f_{i j}$ adalah banyaknya transisi, dan $F_{i}=\underset{j=1}{\stackrel{s}{s}} f_{i j} ; i, j=1,2, \ldots, s$.

Peluang $X_{t+1}$ berada pada keadaan $j$ jika diketahui $X_{t}$ berada pada keadaan $i$, disebut peluang transisi satulangkah, yang dinyatakan dengan $p_{i j}^{(t, t+1)}$, yaitu:

$t_{i j}^{(t, t+1)}=\operatorname{Pr}\left\{X_{t+1}=j \mid X_{t}=i\right\}$, dan peluang transisi $n$-langkah adalah $t_{i j}^{(t, t+n)}=\operatorname{Pr}\left\{X_{t+n}=j \mid X_{t}=i\right\}$.

Dengan menggunakan Teorema Chapman-Kolmogorof, maka matriks peluang transisi $n$-langkah adalah:

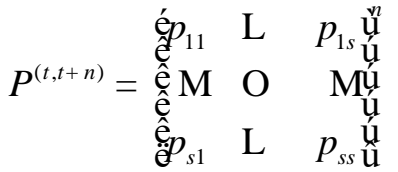

Jika rantai Markov adalah ergodik, maka untuk $n ® ¥ ; p_{i j}^{(t, t+1)}$ akan konvergen ke suatu nilai $\tilde{O}_{j}$ yang hanya tergantung pada nilai $j$ [14]. Nilai-nilai dari $\tilde{O}_{j}$ merupakan nilai dari keadaan-tunak system.

\subsubsection{Nilai Harapan Masa Tinggal (NHMT)}

Misalkan $p_{i j}$ adalah peluang transisi rantai Markov $\left\{X_{t}\right\}$ dari keadaan $i$ ke keadaan $j$, dan $R_{j}$ adalah masa tinggal keadaan $j$, maka

$$
\operatorname{Pr}\left(R_{j}=n\right)=\operatorname{Pr}\left(X_{t+1}=j \mid X_{t}=j\right\}=\ldots=\operatorname{Pr}\left(X_{t+n}{ }^{1} \quad j \mid X_{t+n-1}=j\right)=\left(p_{j j}\right)^{(n-1)}\left(1-p_{j j}\right),
$$

$R_{j}$ berdistribusi geometrik dengan parameter $\left(1-p_{j j}\right)$, sehingga nilai harapan masa tinggal keadaan $j$ adalah

$$
E\left(R_{j} \mid X_{t}\right)=\frac{1}{\left(1-p_{j j}\right)} ;[13]
$$

\subsubsection{Nilai Harapan Masa Perulangan Pertama (NHMPP)}

Misalkan variable acak $t(j)$ adalah banyaknya transisi yang diperlukan untuk mencapai keadaan $j$ didefinisikan sebagai $t(j)=\inf \left\{t^{3} 1 \mid X_{t}=j\right\}$, maka waktu $t(j)$ yang disimbolkan dengan $T_{i j}$ disebut masa perulangan pertama dari keadaan $i$ ke keadaan $j$. Nilai harapan dari $T_{i j}$ didefinisikan sebagai $M_{i j}=E\left[T_{i j}=n\right]=1+\underset{\substack{k=1 \\ k^{1} j}}{\stackrel{s}{a}} p_{i k} M_{k j}, " i, j=1,2, \ldots, s$

atau dalam bentuk matriks:

$$
M=E+P\left(M-M_{d}\right)
$$

dimana $M=\left(M_{i j}\right), E=$ matriks identitas, $P=\left(p_{i j}\right)$, dan $M_{d}=M_{j j}$ (Wahidah, dkk.2 2013)

Indikator yang digunakan dalam penelitian ini untuk mengukur tingkat kenyamanan adalah Temperature Humidity Index (THI). THI merupakan salah satu indeks untuk merepresentasikan tingkat kenyamanan. Indeks ini menggunakan besaran suhu dan kelembaban relatif yang dikaitkan dengan tingkat kenyamanan yang dirasakan populasi manusia di wilayah perkoataan [8]. THI dihitung dengan menggunakan rumus [15], yaitu 


$$
T H I=0.8 T+\frac{H d^{\prime} T}{500},
$$

Dimana $T$ adalah suhu dalam ${ }^{\circ} \mathrm{C}, \mathrm{Hd}$ adalah kelembaban relative dalam $\%$.

Secara empiris, Emmanuel dalam [12] menghubungkan nilai THI dengan kenyamanan populasi seperti dalam Tabel 1

Tabel 1. Nilai batas kategori tingkat kenyamanan

\begin{tabular}{ccc}
\hline Nilai THI $\left({ }^{\mathbf{0}} \mathbf{C}\right)$ & KATEGORI KENYAMANAN & Presepsi \\
\hline $21-24$ & Nyaman & $100 \%$ populasi merasa nyaman \\
\hline $25-27$ & Cukup nyaman & $50 \%$ populasi merasa nyaman \\
\hline$>27$ & Tidak nyaman & $0 \%$ populasi merasa nyaman \\
\hline
\end{tabular}

\subsection{Lokasi dan Sumber Data}

Lokasi penelitian adalah Kota Majene, Provinsi Sulawesi Barat, yang terletak diantara $2^{\circ} 38^{\prime} 45^{\prime \prime}$ dan $3^{0} 38^{\prime} 15^{\prime}$ LS, dan antara $118^{\circ} 45^{\prime} 00^{\prime \prime}$ dan $119^{\circ} 05^{\prime} 00^{\prime \prime}$ BT, seperti pada Gambar 1 [16]. Data suhu udara dan kelembaban relatif yang digunakan dalam penelitian ini diambil dari stasiun Badan Meteorologi dan Geofisika (BMKG) kabupaten Majene untuk periode 1983 - 2011. Stasiun BMKG Majene terletak pada 3033'21" LS, 118058'50" BT dan elevasi 29.

\subsection{Langkah Analisis}

Langkah-langkah analisis yang dilakukan:

(i) Mencari nilai THI dari data temperature dan kelembaban relative menggunakan persamaan (8).

(ii) Mengkategorikan nilai THI berdasarkan Tabel 1

(iii) Menentukan keadaan berdasarkan kategori tingkat kenyamanan untuk mengkonstruksi rantai Markov.

(iv) Mengestimasi nilai-nilai peluang transisi keadaan.

(v) Menentukan peluang keadaan-tunak dari system.

(vi) Menghitung nilai harapan masa tinggal.

(vii) Menghitung nilai harapan masa perulangan pertama.

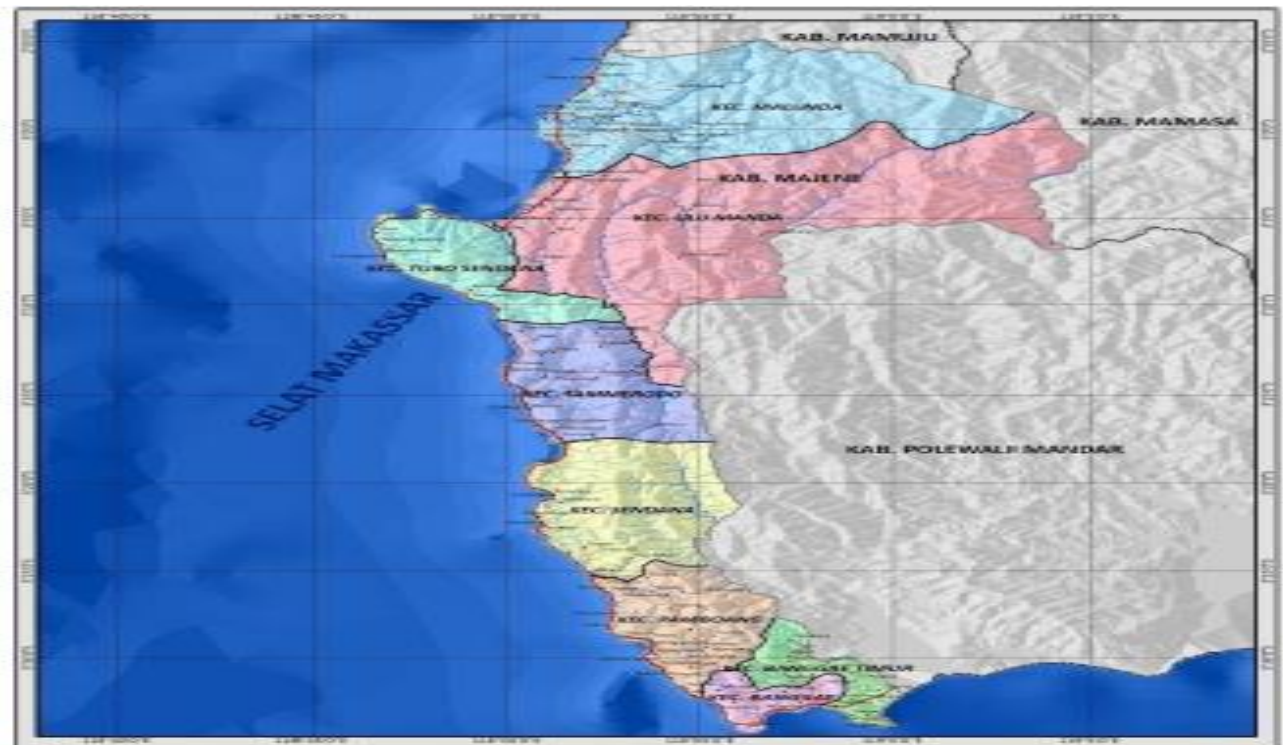

Gambar 1. Peta lokasi Kabupaten Majene

\section{HASIL DAN PEMBAHASAN}

Rentang kategori tingkat kenyamanan dari nilai THI yang digunakan dalam kajian ini adalah dari nilai 21 sampai dengan 30, yang terbagi dalam 3 kategori, yaitu kategori nyaman, cukup nyaman dan tidak nyaman. Kategori kenyamanan tersebut dijadikan sebagai state atau keadaan dari model rantai Markov yang digunakan dalam kajian ini. Pola nilai rata-rata THI bulanan di Kota Majene setiap tahun terdapat dalam Gambar 2. Nilai rata-rata THI bulanan pada Gambar 2 menunjukkan pola bimodal dengan puncak pada bulan 
Mei, Oktober_dan November. Nilai THI terendah terjadi pada bulan Juli dan Agustus. Kategori tidak nyaman terjadi pada bulan Oktober dan November, sementara di bulan-bulan lain masuk dalam kategori cukup nyaman.

Berdasarkan Gambar 3, trend tingkat kenyamanan di Kota Majene dari tahun 1983 sampai tahun 2011 tidak menunjukkan adanya trend naik ataupun turun. Tingkat kenyamanan di Kota Majene dari tahun ketahun hanya berfluktuasi disekitar kategori cukup nyaman dan kategori tidak nyaman.

Nilai peluang keadaan-tunak kategori tingkat kenyamanan yang merupakan peluang terjadinya ketiga kategori tingkat kenyamanan di Kota Majene, terdapat dalam Tabel 2. Kategori cukup nyaman mempunyai peluang terbesar untuk terjadi di Kota Majene, yaitu sekitar 70\%, sedangkan kategori tidak nyaman dan nyaman masing-masing hanya mempunyai peluang untuk terjadi sebesar $25 \%$ dan $5 \%$.

Nilai NHMT yang menyatakan durasi kategori tingkat kenyamanan terjadi di Kota Majene ada juga dalam Tabel 2. Nilai NHMT terbesar, yakni kategori cukup nyaman sebesar 5. Hal ini menunjukkan bahwa kategori cukup nyaman di Kota Majene mempunyai durasi terlama untuk terjadi, yaitu sekitar selama 5 hari sebelum berpindah ke kategori lain. Sementara kategori nyaman hanya mempunyai nilai harapan durasi terjadi selama sekitar 1,41 hari saja sebelum berpindah ke kategori tingkat kenyamanan yang lain.

Nilai terakhir dalam Tabel 2 adalah nilai NHMPP, yaitu nilai yang menyatakan rata-rata durasi suatu kategori tingkat kenyamanan di Kota Majene akan terjadi kembali setelah pernah terjadi sebelumnya. Kategori nyaman mempunyai nilai NHMPP yang terbesar, yaitu 19,8 hari. Ini menunjukkan bahwa kategori nyaman di Kota Majene mempunyai durasi terlama untuk muncul kembali setealah pernah terjadi sebelumnya, yaitu sekitar 19,8 hari. Sementara kategori cukup nyaman di Kota Majene mempunyai durasi tercepat untuk muncul kembali setelah pernah terjadi sebelumnya, yaitu hanya sekitar 1,43 hari.

Tabel 2. Peluang keadaan tunak, nilai NHMT dan nilai NHMPP pada tiap kategori

\begin{tabular}{cccc}
\hline $\begin{array}{c}\text { KATEGORI } \\
\text { KENYAMANAN }\end{array}$ & PELUANG KEADAAN TUNAK & NHMT (harian) & NHMPP (harian) \\
\hline Nyaman & 0,05 & 1,41 & 19,80 \\
\hline Cukup nyaman & 0,70 & 5,00 & 1,43 \\
\hline Tidak Nyaman & 0,25 & 3,99 & 3,99 \\
\hline
\end{tabular}

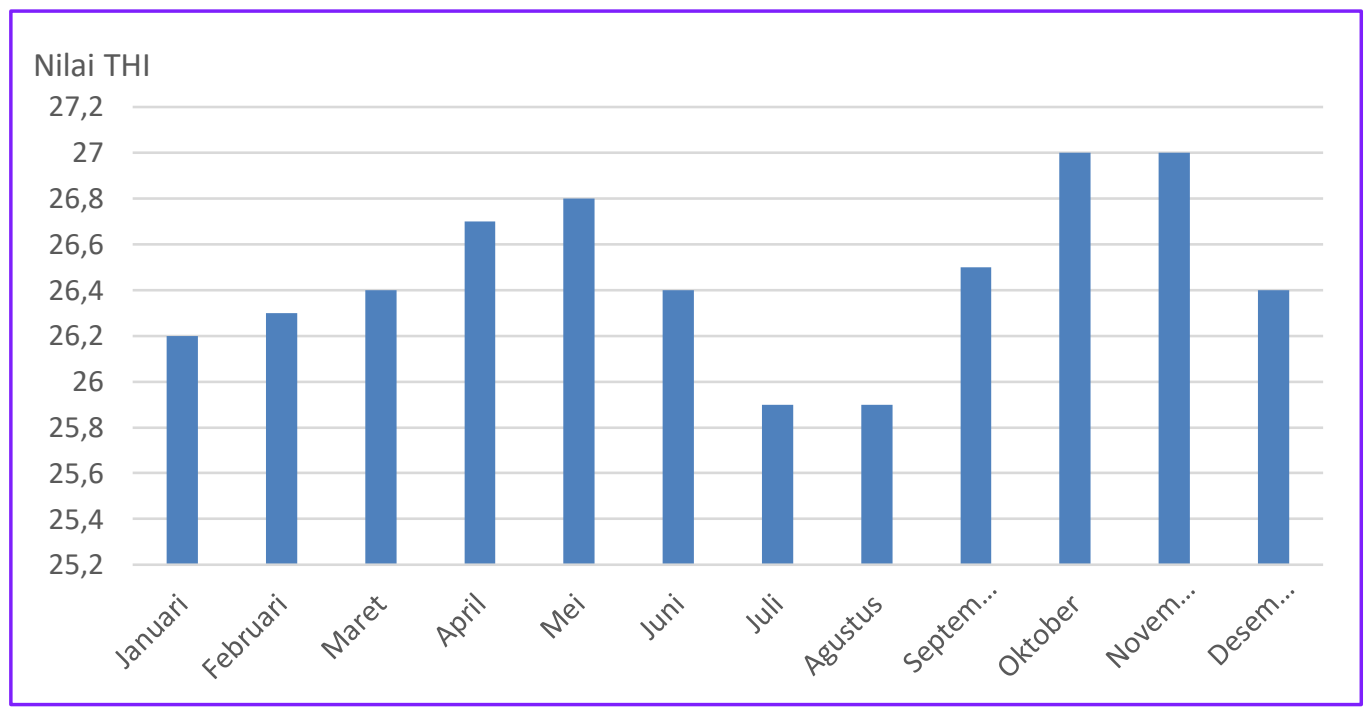

Gambar 2. Pola nilai THI bulanan Kota Majene 


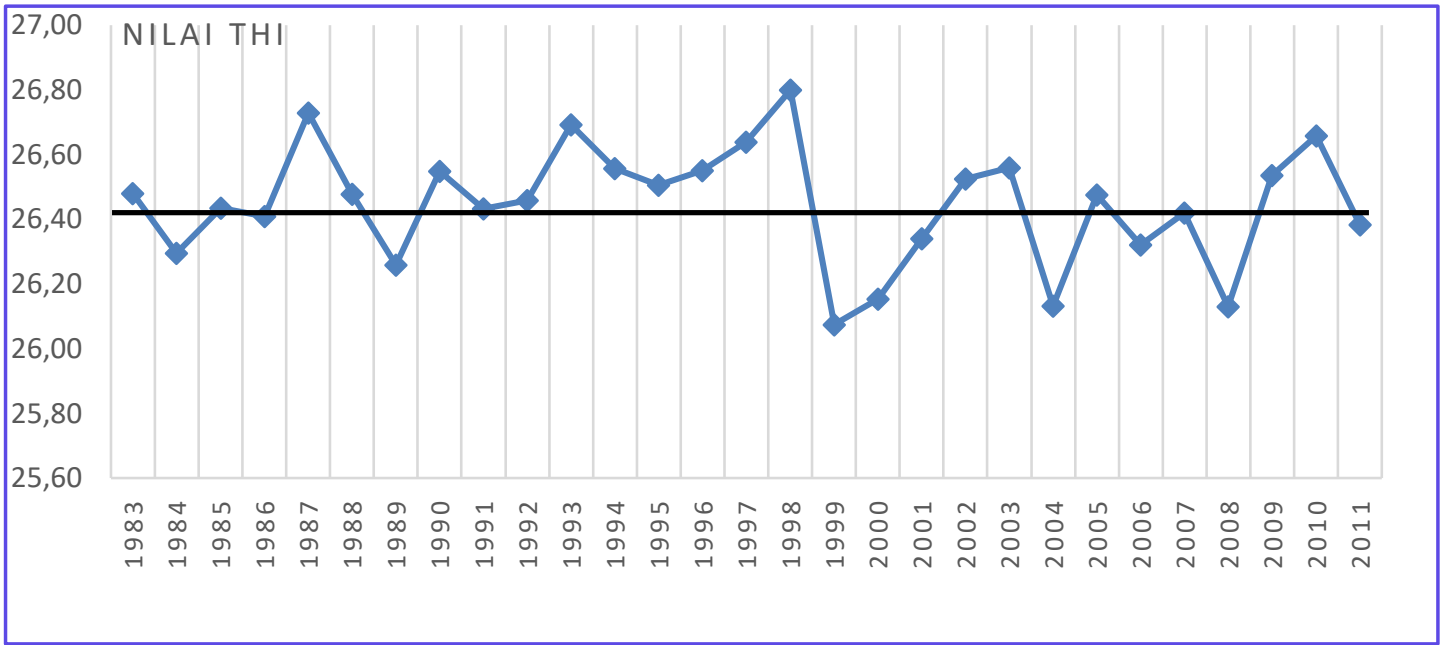

Gambar 3. Trend nilai rata-rata THI Kota Majene 1983 - 2012

\section{KESIMPULAN}

Dalam penelitian ini, model rantai Markov digunakan untuk menganalisis karakteristik tingkat kenyamanan di Kota Majene dengan menganalisis peluang dari 3 kategori tingkat kenyamanan berdasarkan Temperature Humidity Index. Rerata nilai THI terbesar terjadi pada bulan Oktober dan November setiap tahun. Sementara nilai THI terendah terjadi pada bulan Mei setiap tahunnya. Trend tingkat kenyamanan sepanjang tahun 1983 - 2011 cenderung stagnan di kategori cukup nyaman.

Kategori cukup nyaman merupakan kategori tingkat kenyamanan yang paling berpeluang untuk terjadi, sementara kategori nyaman yang paling kecil peluang terjadinya. Nilai NHMT dan NHMPP juga memperlihatkan bahwa kategori cukup nyaman mempunyai durasi terpanjang kemunculannya dan mempunyai durasi terpendek untuk muncul kembali setelah kemunculan sebelumnya. Sementara kategori nyaman mempunyai durasi terpendek kemunculannya, dan mempunyai durasi terlama untuk muncul kembali setelah kemunculan sebelumnya.

\section{DAFTAR PUSTAKA}

[1] Hasan, H., Che Nordin, M. A., Mohd Salleh, N. H. "Modelling Daily Maximum Temperature for Thermal Comfort in Northern Malaysia". Adv. Environ. Biol., 9(26), 12-18, 2015

[2] Semenov, M. A. and Barrow, E.M, "Use of a stochastic weather generator in the development of climate change scenarios" Climatic Change, 35(4): 397-414, 1997.

[3] Keith, D. A., et. al.” Predicting extinction risks under climate change: coupling stochastic population models with dynamic bioclimatic habitat models" Biology Letters, 4(5): 560-563, 2008.

[4] Wilks, D., "Adapting stochastic weather generation algorithms for climate change studies" Climatic Change, 22: 67-84, 1992.

[5] Chulsang, Y, Jinwook, L, Yonghun, R, "Markov Chain Decomposition of Monthly Rainfall into Daily Rainfall: Evolution of Climate Change Impact", Advances in Meteorology, vol. 2016, 2016.

[6] Mieruch, S, et. al, "Markov chain analysis of regional climates", Nonlinear Processes in Geophysics, vol. 17, 651-661, 2010.

[7] Florescu, I.I. and Levin, F. "Estimation procedure for a hidden Markov chain model with applications to finance, climate data and earthquake analysis”. 2008, Retrieved June 28, 2020, from http://www.math.ubordeaux1.fr/ pdelmora/hmm-finance.pdf

[8] Wati, T dan Fatkhuroyan. "Analisis Tingkat Kenyamanan di DKI Jakarta Berdasarkan Indeks THI (Temperature Humidity Index), "Jurnal Ilmu Lingkungan" 15(1), 57- 63, 2017.

[9] Matzarakis, A., H. Mayer and M.G. Iziomon, "Applications of a universal thermal index: physiological equivalent temperature" International Journal of Biometeorology, 43(2): 76-84, 1999.

[10] American National Standard Institute (ANSI), ASHRAE Standard, 2013.

[11] Thom, E. C, The discomfort index, Weatherwise 12(2), 57-60, 1959

[12] Effendy S, Bey, A, Zain, A.F.M, Santosa, I, "Peranan ruang terbuka hijau dalam mengendalikan suhu udara dan urban heat island wilayah JABOTABEK", J Agrom Indonesia. 20(1):23-33, 2006.

[13] W. Sanusi, A. A. Jemain, W. Z. W. Zin, M. Zahari, "The Drought Characteristics using the First-Order Homogeneous Markov Chain of Monthly Rainfall Data in Peninsular Malaysia”, Water Resource Management, Vol. 29: 1523 - 1539, 2015.

[14] Ross, S. M., Introduction to Probability Models, 9th ed, Academic Press, California, 2007

[15] Nieuwolt, S, Tropical Climatology. London: Wiley; 1977.

[16] Badan Pusat Statistik, Majene Dalam Angka 2018, Majene: BPS Kabupaten Majene, 2018. 